\title{
Estimation of Mercury Intake from Consumption of Fish and Seafood in Russia
}

\author{
Anatoliy V. Gorbunov¹, Boris V. Ermolaev¹, Sergey M. Lyapunov', Olga I. Okina1, \\ Sergey S. Pavlov ${ }^{2}$, Marina V. Frontasyeva ${ }^{2}$ \\ ${ }^{1}$ Geological Institute, Russian Academy of Sciences, Moscow, Russia \\ 2Joint Institute for Nuclear Research, Dubna, Russia \\ Email: marina@nf.jinr.ru
}

Received 5 April 2016; accepted 3 June 2016; published 6 June 2016

Copyright (C) 2016 by authors and Scientific Research Publishing Inc.

This work is licensed under the Creative Commons Attribution International License (CC BY).

http://creativecommons.org/licenses/by/4.0/

c) (†) Open Access

\begin{abstract}
Data on the mercury concentration in freshwater and marine fish and seafood on the territory of Russia are presented. The level and pattern of the fish and seafood consumption in various regions of Russia are found from the analysis of open statistics. Regions with the maximum and minimum consumption of fish products are established. Mercury intake from these products in a human organism is calculated. It is shown that at the current level and pattern of the diet in Russia fish cannot be a source of high mercury concentrations in a human organism.
\end{abstract}

\section{Keywords}

Mercury, Marine and Freshwater Fish, Seafood, Consumption Level, Human Organism, Intake

\section{Introduction}

At present the impact of large (toxic) doses of mercury on the human body (neurological syndrome caused by severe mercury poisoning, Chisso-Minamata disease) is well studied. But these events are rather local over the area and time. Chronic exposure to low, almost background doses result in gradual accumulation of mercury in the body. The constant consumption of fish, especially sea fish, and particularly large predatory sea fish (shark, tuna, mackerel) can lead to increased regular intake of mercury in the human body. And this is a kind of a global impact, and, to the best of our knowledge, the WHO and other organizations have come precisely to this conclusion. For Russia, the data on of the impact of fish consumption on the balance of mercury in the human body are completely absent, as are the data on mercury concentrations in fish consumed by Russian population. In order to understand what is happening in this area, it is necessary i) to estimate the concentration of mercury in the main fish species consumed by the population; ii) to analyze the level and specificity of consumption in different regions, and iii) to calculate the intake and draw conclusions. This was performed in our study.

How to cite this paper: Gorbunov, A.V., Ermolaev, B.V., Lyapunov, S.M., Okina, O.I., Pavlov, S.S. and Frontasyeva, M.V. (2016) Estimation of Mercury Intake from Consumption of Fish and Seafood in Russia. Food and Nutrition Sciences, 7, 516-523. http://dx.doi.org/10.4236/fns.2016.77053 
Mercury and its compounds are highly toxic and are assigned to the highest hazard class 1 . Mercury holds a specific place among heavy and toxic metals. It has unique properties, such as variety of forms, ubiquity, higher ability of distribution and transfer in the environment, and wide range of negative effects on organisms. The level of mercury intake by humans on a particular territory depends on many factors, such as presence of mercury deposits, chemical factories, heat and power plants, dumps, and mercury waste burial places. The main home sources of mercury are luminescent lamps and mercury thermometers [1]-[3]. However, in most regions of Russia there are no such sources (as, for example, deposits) or they cause only limited local pollution. Therefore, some researchers now believe that people take in mercury mainly with food, especially with fish and seafood [4]-[8]. Accumulation of mercury in fish and seafood directly depends on the input of mercury into reservoirs and is due to both natural and man-made factors. Mercury comes into reservoirs mainly through atmospheric precipitation resulting from general degassing of the Earth's crust and oceans, volcanic activity, and industrial emission into the atmosphere. After coming into a reservoir, mercury undergoes transformation [9] [10] in three main directions: it is reduced to the elementary state and escapes into the atmosphere, forms strong insoluble compounds (sulfides) and is deposited in the bottom sediment, and is sorbed on the surface of bacterial membranes and transforms into a mercury organic compound (methylmercury). Methylmercury accumulates in water-inhabiting organisms (plants, benthos, animals) and is ultimately concentrated at high levels of the food chain, namely, in fish. It is also reported that the mercury concentration in predator fish is several times higher than that in their food [11]. The fish growth intensity can also be regarded as a decisive factor affecting the mercury accumulation level. By the age of 5 years fast-growing species (freshwater pike perch, pike) can weigh as much as 1.0 to $1.5 \mathrm{~kg}$ while the river perch weighs only $200 \mathrm{~g}$. Accordingly, the mercury concentration in the former fish can be higher. The same applies to marine species - sea perch, tuna, shark. In the current Russian literature there are very few data on mercury accumulation in freshwater and marine fish and seafood, and accordingly on mercury intake in their consumers.

The goal of this work was to estimate the mercury intake from fish and seafood in various population groups on the territory of Russia. The following objectives were solved in the process of the work:

- Estimation of the fish and seafood consumption level for different population groups.

- Determination of the fish and seafood consumption pattern.

- Sampling of fish products most often consumed in various population groups and determination of the mercury concentration in the samples.

- Calculation of the mercury intake in the human organism for different groups of the Russian population.

\section{Materials and Methods}

\subsection{Sampling}

Fish samples were taken in the retail outlets in various towns of European and Asian Russia on a random sampling basis without connection to the manufacturer (exactly as the population buys fish and seafood). Marine fish and seafood samples were taken in Moscow, Podolsk, Kaluga, Gus-Khrustalny, Arkhangelsk, Sochi, Khanty-Mansiisk, Khabarovsk, and Vladivostok. Freshwater fish were partially taken from retail outlets and partially caught in European Russia’s rivers of Oka, Moskva, Osetr, Volga, and Akhtuba.

The samples were placed into polyethylene zip-lock bags, cleaned from external dirty, and washed with distilled water. To withstand long transportation, the samples were frozen at $-20^{\circ} \mathrm{C}$. They were not dried and crushed and were analyzed at their natural humidity. The total list and number of fish and seafood samples is presented in Table 1.

\subsection{Analysis of the Samples}

Mercury concentration was measured by the method of atomic absorption with "cold" vapor using the Yuliya-5K mercury analyzer (Metrologiya Company, Russia). The samples were mineralized by a mixture of the nitric (extra pure) and perchloric (chemically pure) acids while being heated in flasks with a backflow condenser. Absorption of the radiation with a wavelength of $253.7 \mathrm{~nm}$ was measured after the reduction of mercury by tin chloride $\left(\mathrm{SnCl}_{2} \times 2 \mathrm{H}_{2} \mathrm{O}\right.$, analytically pure). The instrument was calibrated using a series of graduation mercury solutions prepared with the aid of MSO 0304:2002 (Ekros Company, Russia) [8]. The quality control of the analysis results was performed by analyzing "blank" samples, standard and control samples of biological mate- 
Table 1. Sampled fish and seafood.

\begin{tabular}{|c|c|c|c|}
\hline No. & Species & No. & Species \\
\hline & MARINE FISH & 27 & Asp, $\Pi$ I $=6$ \\
\hline 1 & Grey mullet, n = 7 & 28 & Zope, II $=5$ \\
\hline 2 & Plaice, $n=5$ & 29 & Coho salmon, $\Pi=6$ \\
\hline 3 & Mackerel icefish, $n=6$ & 30 & Carp, $\Pi=11$ \\
\hline 4 & Butterfish, $\Pi=5$ & 31 & Crucian carp, $\Pi=9$ \\
\hline 5 & Alaska pollack, $n=10$ & 32 & Bream, $I=10$ \\
\hline 6 & Cod icefish, $\Pi=3$ & 33 & Muksun, $\Pi$ I = 5 \\
\hline 7 & Ocean perch, $n=6$ & 34 & Perch, $I$ = 11 \\
\hline 8 & Halibut, $\Pi=7$ & 35 & Sturgeon, $\Pi=7$ \\
\hline 9 & Haddock, $\Pi=13$ & 36 & Roach, $\Pi$ I $=8$ \\
\hline 10 & Blue whiting, $\Pi=5$ & 37 & Common carp, $\Pi=6$ \\
\hline 11 & Sardine, $\Pi=5$ & 38 & Whitefish, $\Pi=\mathbf{3}$ \\
\hline 12 & Herring, $n=5$ & 39 & Catfish, $\Pi=5$ \\
\hline 13 & Mackerel, II = 11 & 40 & Zander, $\Pi=5$ \\
\hline 14 & Tilapia, $\Pi=5$ & 41 & Peled, $I=4$ \\
\hline 15 & Cod, $n=13$ & 42 & Trout, $\Pi=5$ \\
\hline 16 & Hake, $I I=11$ & 43 & Pike, $I I=7$ \\
\hline & SEAFOOD & 44 & Sabrefish, $\Pi=7$ \\
\hline 17 & Mussels, $\mathrm{I}=9$ & 45 & Crayfish, $\Pi=9$ \\
\hline 18 & Scallops, $I I=7$ & & ROE \\
\hline 19 & Red king crab, $\Pi=4$ & 46 & Salmon roe,, $\mathrm{I}=5$ \\
\hline 20 & Shrimps, $\mathrm{n}=17$ & 47 & Chum salmon roe, $\Pi=7$ \\
\hline 21 & Octopus, $\Pi=5$ & 48 & Ruffe roe, $\Pi=3$ \\
\hline 22 & Squid, $n=19$ & 49 & Roach roe, $I I=4$ \\
\hline 23 & Cuttlefish, $I=3$ & \multicolumn{2}{|c|}{ CANNED FISH } \\
\hline & RIVER AND MIGRATORY FISH & 50 & Gobies in tomato sauce, $\Pi=12$ \\
\hline 24 & Goby, $\Pi=5$ & 51 & Tuna, $\Pi=3$ \\
\hline 25 & Humpback salmon, I = 13 & 52 & Salmon, $\Pi=15$ \\
\hline 26 & Ruffe, I $=9$ & 53 & Pacific saury in oil, $I I=7$ \\
\hline
\end{tabular}

rials with certified mercury content. International standard and control samples were analyzed together with the samples under investigation.

\subsection{Results and Discussion}

The FAO/WHO provisional tolerable weekly intake for total mercury was set to be $5 \mu \mathrm{g}$ per kg of body weight (3.3 $\mu$ g for methylmercury) [4] [12] [13]. According to various estimations, there is 10 - 15 mg of mercury in the human body; the toxic effect arises from the intake of $0.4 \mathrm{mg} / \mathrm{day}$. Table 2 lists maximum permissible concentrations (MPCs) of mercury set in Russia for various fishes and fish products [14]. 
Table 2. MPCs of mercury in fish and seafood.

\begin{tabular}{ccc}
\hline \multicolumn{1}{c}{ Products } & MPC, mg/kg (ppm) \\
\hline Live, refrigerated, frozen, minced fish, fish fillet & Freshwater non-predatory & 0.3 \\
& Freshwater predatory & 0.6 \\
Fish roe and milt and products thereof & Marine & 0.5 \\
Fish liver and products thereof & Tuna, swordfish, beluga & 0.2 \\
Shellfish & 0.5 \\
Canned fish in prefabricated tin containers & 0.2 \\
\hline
\end{tabular}

In Table 3 the results of our marine fish and seafood analysis are compared with the literature data. It is first of all noteworthy that our results and the literature data rather well. As is evident from Table 3, the average mercury concentrations are no higher than the permissible levels presented in Table 2. Note however that maximum mercury concentrations in halibut, humpback salmon, herring, and ocean perch are quite close to the MPC. The same applies to canned tuna as well. The lowest mercury concentration is typical of shellfish and their roe.

Table 4 shows the results from our freshwater fish analysis. The lowest mercury concentrations are typical of ruffe and ruffe and roach roe while the highest concentrations are typical of sturgeon and catfish. No excess of the MPC is observed. Evaluation of data shown in Table 3 and Table 4 shows that, for the first, the authors' data fairly well correlate with the world literature data, and, secondly, it is shown that the highest concentration of mercury are characteristic for carnivorous fish, and the lowest ones-for molluscs, crustaceans and calves.

The level and pattern of fish and seafood consumption depend on a lot factors, such as the habitation region, availability of these products in the retail network, income level of the population, mentality, and adherence to traditional diets. In Russia, fish and seafood account for an average of $2.5 \%$ - 3\% of the population diet [18] [19]. Table 5 presents the patterns and annual consumption of fish and fish products in different regions of Russia (data of 2012).

The intake of mercury in the human organism was calculated with the data from Tables 3-5 using the formula

$$
V=P \times \mathrm{Cav},
$$

where $V$ is the mercury intake, $\mu \mathrm{g} /$ day;

$P$ is the consumption of fish and seafood, $\mathrm{kg} / \mathrm{day}$ (Table 5);

$\mathrm{Cav}$ is the arithmetic average of the mercury concentration in the total fish consumption, $\mu \mathrm{g} / \mathrm{kg}$ (based on Tables 3-5).

The value of $\mathrm{P}$ was converted from $\mathrm{kg} / \mathrm{year}$ to $\mathrm{kg} / \mathrm{day}$. The quantity Cav was calculated with allowance for the consumption pattern in the given region (Table 5) and mercury concentration in each particular fish (Table 3 and Table 4). For example, according to Table 5, the main consumption pattern items in Moscow are hake, cod, Alaska pollack, herring, humpback salmon, mackerel, squids, and shrimps. Mercury concentrations in these fishes and seafoods are listed in Table 3 and Table 4. For the sake of simplicity, we assume that they all are consumed in equal proportion. Thus,

$$
\mathrm{Cav}=(C 1+C 2+\cdots C n) / n
$$

Table 6 presents the results of calculating the mercury intake from fish and seafood in the human organism in different regions of Russia. As was already shown above, the safe weekly mercury intake in the human organism is $5 \mu \mathrm{g}$ per $\mathrm{kg}$ of body weight. The conversion to the average weight of an individual and to the daily intake yields the safe intake of $50 \mu \mathrm{g} /$ day. The data in Table 6 show that in no region the mercury intake from fish and seafood in the human organism exceeds the safe value. Moreover, in most regions the actual mercury intake from fish and seafood is 10 - 20 times lower than the safe threshold. 
Table 3. Mercury concentration in marine fish, canned fish, and seafood, $\mu \mathrm{g} / \mathrm{kg}(\mathrm{ppb})$.

\begin{tabular}{|c|c|c|c|}
\hline No. & Item & Our data & Literature data $[15]-[17]$ \\
\hline 1 & Plaice, $n=5$ & $45 \pm 21$ & $56 \pm 45$ \\
\hline 2 & Grey mullet, n = 7 & $43 \pm 23$ & $52 \pm 27$ \\
\hline 3 & Mackerel icefish, $n=6$ & $110 \pm 35$ & - \\
\hline 4 & Butterfish, II $=5$ & $79 \pm 56$ & $58 \pm 49$ \\
\hline 5 & Alaska pollack, $n=10$ & $40 \pm 16$ & $31 \pm 30$ \\
\hline 6 & Cod icefish, $I=6$ & $11 \pm 8$ & - \\
\hline 7 & Ocean perch, $n=6$ & $189 \pm 91$ & $308 \pm 299$ \\
\hline 8 & Halibut, $I I=7$ & $203 \pm 182$ & $241 \pm 225$ \\
\hline 9 & Haddock, II = 13 & $42 \pm 32$ & $55 \pm 33$ \\
\hline 10 & Blue whiting, $\Pi=5$ & $44 \pm 13$ & - \\
\hline 11 & Sardine, $\Pi=\mathbf{5}$ & $28 \pm 22$ & $13 \pm 13$ \\
\hline 12 & Herring, $n=5$ & $17 \pm 10$ & $84 \pm 80$ \\
\hline 13 & Mackerel, $\mathrm{I}=11$ & $154 \pm 110$ & $88 \pm 85$ \\
\hline 14 & Tilapia, $\mathbf{I}=\mathbf{5}$ & $18 \pm 15$ & $13 \pm 12$ \\
\hline 15 & Cod, $n=13$ & $34 \pm 12$ & $111 \pm 150$ \\
\hline 16 & Hake, $\Pi=11$ & $33 \pm 15$ & $79 \pm 64$ \\
\hline \multicolumn{4}{|c|}{ Roe } \\
\hline 17 & Salmon roe, $\Pi=5$ & $3.1 \pm 1.2$ & - \\
\hline 18 & Chum salmon roe, $\mathrm{I}=7$ & $3.3 \pm 1.3$ & - \\
\hline \multicolumn{4}{|c|}{ Seafood } \\
\hline 19 & Red king crab, $I=4$ & $12 \pm 5.3$ & $65 \pm 96$ \\
\hline 20 & Shrimps, $\mathbf{n}=17$ & $13 \pm 5$ & $9 \pm 13$ \\
\hline 21 & Scallops, $\Pi=7$ & $9 \pm 3.5$ & $3 \pm 7$ \\
\hline 22 & Mussels, $\Pi$ I $=9$ & $6 \pm 4.5$ & $9 \pm 9$ \\
\hline 23 & Octopus, II $=5$ & $23 \pm 10$ & - \\
\hline 24 & Squid tentacles, $I=3$ & $18 \pm 7.7$ & - \\
\hline 25 & Squid, $n=19$ & $21 \pm 7.5$ & $23 \pm 22$ \\
\hline 26 & Cuttlefish, $\Pi=3$ & $28 \pm 15$ & - \\
\hline \multicolumn{4}{|c|}{ Canned fish } \\
\hline 27 & Pacific saury in oil, $\Pi=7$ & $23 \pm 8.5$ & - \\
\hline 28 & Gobies in tomato sauce, $\Pi=12$ & $7 \pm 2.3$ & - \\
\hline 29 & Tuna, $\Pi=\mathbf{3}$ & $273 \pm 251$ & $350 \pm 345$ \\
\hline 30 & Salmon, II = 15 & $15 \pm 9$ & $8 \pm 7$ \\
\hline
\end{tabular}


Table 4. Mercury concentration in freshwater and migratory fish, $\mu \mathrm{g} / \mathrm{kg}(\mathrm{ppb})$.

\begin{tabular}{|c|c|c|c|}
\hline No. & Item & Our data & Literature data [15]-[17] \\
\hline 1 & Humpback salmon, $\quad$ I $=13$ & $185 \pm 180$ & $235 \pm 211$ \\
\hline 2 & Goby, II $=5$ & $57 \pm 35$ & - \\
\hline 3 & Ruffe, $\Pi=9$ & $11 \pm 4$ & - \\
\hline 4 & Asp, $\Pi=6$ & $51 \pm 20$ & - \\
\hline 5 & Coho salmon, $I=\mathbf{3}$ & $69 \pm 61$ & - \\
\hline 6 & Carp, II $=11$ & $98 \pm 53$ & $110 \pm 69$ \\
\hline 7 & Crucian carp,,$\Pi=9$ & $31 \pm 11$ & - \\
\hline 8 & Bream, $I=10$ & $45 \pm 13$ & - \\
\hline 9 & Muksun, $\Pi$ I $=5$ & $40 \pm 32$ & - \\
\hline 10 & Perch, $\Pi=11$ & $125 \pm 61$ & $150 \pm 83$ \\
\hline 11 & Sturgeon, $\Pi=7$ & $189 \pm 87$ & - \\
\hline 12 & Roach, $\Pi$ I $=8$ & $83 \pm 35$ & - \\
\hline 13 & Common carp, $\Pi=6$ & $150 \pm 110$ & - \\
\hline 14 & Whitefish, $n=3$ & $73 \pm 63$ & $89 \pm 84$ \\
\hline 15 & Zope, II $=5$ & $32 \pm 11$ & - \\
\hline 16 & Catfish, $\Pi=5$ & $260 \pm 83$ & - \\
\hline 17 & Zander, $\mathbf{I}=5$ & $152 \pm 29$ & - \\
\hline 18 & Peled, $\Pi=5$ & $28 \pm 25$ & - \\
\hline 19 & Trout, $\Pi=5$ & $65 \pm 63$ & $71 \pm 140$ \\
\hline 20 & Sabrefish,,$I=7$ & $42 \pm 15$ & - \\
\hline 21 & Pike, $\Pi=7$ & $110 \pm 56$ & - \\
\hline 22 & Crayfish, $\Pi=9$ & $11 \pm 6.5$ & $33 \pm 12$ \\
\hline \multicolumn{4}{|c|}{ Roe } \\
\hline 23 & Ruffe roe, $I=3$ & $7 \pm 3.5$ & - \\
\hline 24 & Roach roe, $\Pi=4$ & $11 \pm 4.6$ & - \\
\hline 25 & Humpback salmon roe, $\Pi=5$ & $4.5 \pm 1.5$ & - \\
\hline
\end{tabular}

Table 5. Patterns and amount of fish and seafood consumption in different regions of Russia [18]-[22].

\begin{tabular}{|c|c|c|}
\hline Region & $\begin{array}{c}\text { Consumption, } \\
\text { kg/year }\end{array}$ & Consumption pattern \\
\hline Chukot Autonomous Okrug & 58.9 & Whitefishes (coho salmon, muksun, whitefish, peled), salmons \\
\hline Moscow & 30.1 & Hake, cod, haddock, herring, humpback salmon, mackerel, squids, shrimps \\
\hline Far Eastern Federal District & 27.0 & Alaska pollack, hake, cod, salmons, herring \\
\hline Northwestern Federal District & 21.6 & Halibut, plaice, ocean perch, cod, haddock, trout \\
\hline Central Federal District & 20.5 & Cod, haddock, herring, humpback salmon, mackerel, squids, shrimps \\
\hline Urals Federal District & 19.5 & Hake, cod, haddock, herring, mackerel, squids, shrimps \\
\hline St. Petersburg & 17.9 & Hake, cod, haddock, herring, humpback salmon, mackerel, squids, shrimps \\
\hline Average over Russia & 17.1 & Hake, cod, haddock, herring, salmons, mackerel, squids, shrimps \\
\hline Southern Federal District & 16 & Cod, grey mullet, goby, haddock, herring, mackerel, shrimps \\
\hline Siberian Federal District & 14.7 & Whitefishes (coho salmon, muksun, whitefish, peled), salmons, cod, herring \\
\hline Volga Federal District & 12.9 & Common carp, bream, sabrefish, asp, perch, cod, herring \\
\hline North Caucasian Federal District & 7.3 & Alaska pollack, hake, cod, herring \\
\hline
\end{tabular}


Table 6. Intake of Hg from fish and seafood in the human organism in different regions of Russia.

\begin{tabular}{cc} 
Region & Hg intake, \\
\cline { 2 - 2 } Chukot Autonomous Okrug & $\mu g /$ day \\
Moscow & 13 \\
Far Eastern Federal District & 5 \\
Northwestern Federal District & 4.7 \\
Central Federal District & 6 \\
Urals Federal District & 3.9 \\
St. Petersburg & 2.5 \\
Average over Russia & 3.3 \\
Southern Federal District & 3.1 \\
Siberian Federal District & 2.6 \\
Volga Federal District & 2.3 \\
North Caucasian Federal District & 2.4 \\
\hline
\end{tabular}

\section{Conclusions}

All above said lead to the following conclusions:

- The statement that the highest concentration of mercury is a characteristic of predatory fish (both freshwater and ocean) is confirmed. The lowest concentration of mercury is a characteristic of molluscs, crustaceans, and eggs;

- The current level and structure of consumption of fish and seafood by the Russian population cannot be a source of high mercury exposure in humans. Real mercury intake with the consumption of fish and seafood by man at the territory of the Russian Federation is the 5 - 15 times lower than the safe dose according to WHO and FAO;

- However, it is shown that for Russia a low dose intake of mercury through consumption of fish and seafood is characteristic and can be assessed as 1 - $13 \mathrm{mkg} /$ day. Given the fact that mercury is derived from the body very slowly and there is a risk of cumulative mercury accumulation in the body, this phenomenon is requires further additional and thorough investigations.

\section{References}

[1] Pirrone, N. and Mahaffey, K. (2005) Dynamics of Mercury Pollution on Regional and Global Scales: Atmospheric Processes and Human Exposures around the World. Springer, New York.

[2] Yanin, Ye.P. (2005) Mercury in Russia: Resources, Production, Consumption. Mercury. Problems of Geochemistry, Ecology, Analytics. Collection of Papers, IMGRE, Moscow, 5-34 (in Russian).

[3] (2005) Estimation of Mercury Releases to the Environment from the Territory of the Russian Federation. Rostekhnadzor in Collaboration with the Danish Agency for Environmental Protection Agency (DEPA), Copenhagen, 304.

[4] Clarkson, T.W. and Magos, L. (2006) The Toxicology of Mercury and Its Chemical Compounds. Critical Reviews in Toxicology, 36, 609-662. http://dx.doi.org/10.1080/10408440600845619

[5] Selin, N.E., Sunderland, E.M., Knightes, C.D. and Mason, R.P. (2010) Sources of Mercury Exposure for US Seafood Consumers: Implications for Policy. Environmental Health Perspectives, 118, 137-143.

[6] Passos, C.J. and Mergler, D. (2008) Human Mercury Exposure and Adverse Health Effects in the Amazon: A Review. Cadernos de Saúde Pública, 24, S503-S520. http://dx.doi.org/10.1590/s0102-311x2008001600004

[7] Mahaffey, K.R., Clickner, R.P. and Jeffries, R.A. (2009) Adult Women's Blood Mercury Concentrations Vary Regionally in the United States: Association with Patterns of Fish Consumption (NHANES 1999-2004). Environmental Health Perspectives, 117, 47-53. http://dx.doi.org/10.1289/ehp.11674 
[8] Balshaw, S., Edwards, J., Daughtry, B. and Ross, K. (2007) Mercury in Seafood: Mechanisms of Accumulation and Consequences for Consumer Health. Reviews on Environmental Health, 22, 91-113.

[9] Nemova, N.N. (2005) Biochemical Effect of Mercury Accumulation in Fish. NAUKA, Moscow, 161 (in Russian).

[10] Komov, V.T. (1999) Natural and Anthropogenic Acidification of Small North-West Lakes of Russia: Causes, Consequences, Prognosis. PhD Thesis, Saint-Petersburg (in Russian).

[11] Gremyachikh, V.A., Kamshilova, T.B. and Komov, V.T. (2013) Mercury Accumulation in Muscles and Growth Rate of Perches (Perca fluviatilis Linnaeus) in Lakes of the Polistovo-Lovatskoe Raised Bog. Water: Chemistry and Ecology, No. 12, 58-63 (in Russian).

[12] Agadzhanyan, N.A., Veldanova, M.V. and Skal'ny, A.V. (2001) Ecological Portrait of Man and Role of Microelements. MK Scientific Press Ltd., Moscow, 236.

[13] (2013) Addendum for Organic Mercury Compounds (Alkyl and Dialkyl Mercury Compounds). Supplement to the 1999 Toxicological Profile for Mercury. Agency for Toxic Substances and Disease Registry Division of Toxicology and Human Health Sciences, Atlanta, 143. http://www.atsdr.cdc.gov/toxprofiles/mercury_organic_addendum.pdf

[14] SANPIN2.3.2.560-96. http://www.dioxin.ru/doc/sanpin2.3.2.560-96.htm

[15] U.S. FDA (Food and Drug Administration) (1978) National Marine Fisheries Service Survey of Trace Elements in the Fishery Resource (1990-2010) Report 1978.

[16] (2001) The Occurrence of Mercury in the Fishery Resources of the Gulf of Mexico Report 2000. U.S. Food and Drug Administration Center for Food Safety and Applied Nutrition Office of Seafood.

[17] Groth III, E. (2010) Ranking the Contributions of Commercial Fish and Shellfish Varieties to Mercury Exposure in the United States: Implications for Risk Communication. Environmental Research, 110, 226-236. http://dx.doi.org/10.1016/j.envres.2009.12.006

[18] Vtorushina, A.V. (2011) Regional Features of Development of Society of Consumption in Russia: Analysis of Nutrition Structure. Journal of Sociology and Social Anthropology, XIV, 252-259.

[19] Analysis of RF Consumption Basket in 2012-2013. Analytical Review. TEBIZ Group. www.tebiz.ru

[20] Stroev, V.V. (1999) Eco-Economic Substantiation of Provision of Russian Population with Seafood. PhD Thesis of Economic Sciences, Moscow, 177 (in Russian).

[21] (2013) Annual Russian Statistics, 2013. RIOSSTAT, Moscow, 717.

[22] Gershonkov, A.M. and Merkulov, Ye.U. (2014) Analysis of the Consumption of Staple Foods by RF Regions. SocioEconomic Phenomena and Processes, 9, 54-63. 